\title{
BEHAVIOR OF LOAD BEARING WALL FABRICATED FROM LIMESTONE
}

\author{
Sara Fawzey ${ }^{1}$, Wael Ibrahim ${ }^{1}$ \\ ${ }^{1}$ Department of Civil Engineering, Faculty of Engineering, Mataria, Helwan University
}

\begin{abstract}
The construction system of load bearing wall is a widespread system where it is an economic and easy to implement method. The most important construction materials used in building walls bearing system are (stone, clay unit, calcium silicates units and concrete masonry units), in this research it has been studied the behavior and strength of limestone. Limestone found in vast areas of the Egyptian deserts such as the Giza, Saqqara, Tourra, Matrouh and Minya. Therefore, an experimental program consisting of three stages was developed. The first stage includes testing units of limestone to determine their physical and chemical properties. In the second stage, building masonry prisms constructed from limestone used two types of mortar no.1 and 4 mixed according to the Egyptian code for designing and executing masonry works, where the tests conducted (compressive strength, shear strength, tensile strength, in plane and out of plan). As for the third stage, it includes testing six walls under the influence of axial load, as these walls are divided into two groups: the first group was built by using mortar no. 1, while the second group was built by using mortar no. 4; each group is divided into three types of walls. The first type was a solid wall; the second was a wall with a window opening, while the third was a wall with a door opening. The results showed that the compressive strength of walls that were built by using mortar no. 1 is better than those that were built by using mortar no. 4
\end{abstract}

KEYWORDS: Limestone, Load bearing walls, Masonry units, Masonry.

\section{INTRODUCTION}

The limestone has been used since ancient times as a building material; it has been used in building Pyramids, tombs and temples until about the middle of the eighteenth dynast. The wall structural performance under load and strength depends on many factors such as the nature of stone, dimensions of the single block, arrangement in the structure and also the type of mortar that is used to connect the stones [4]. And also the behavior of mortars in stone masonry walls under loading gives ductility to the wall and gives signs before collapse (squeeze of mortar, cracks in stone) and it was found that walls built with thin mortar joints failed without enough warning, which mean that absence of mortar means sudden collapse [4]. In case of using mortar consisting of few amount of lime in additional to cement and sand in the construction of masonry prisms it gave high compressive strength of prisms [5]. For the prisms 
built with weak mortars, failure starts with mortar crushing, which causes localized tensile stresses in the block. These observations lead to the conclusion that the interaction between mortar and block is responsible for the masonry failure [2].

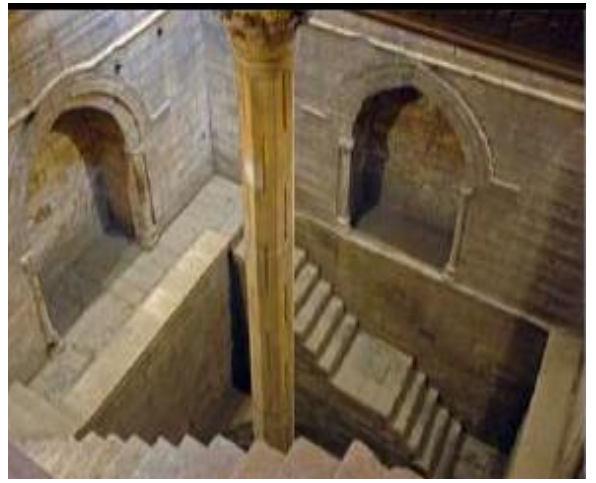

a. The Nile Scale

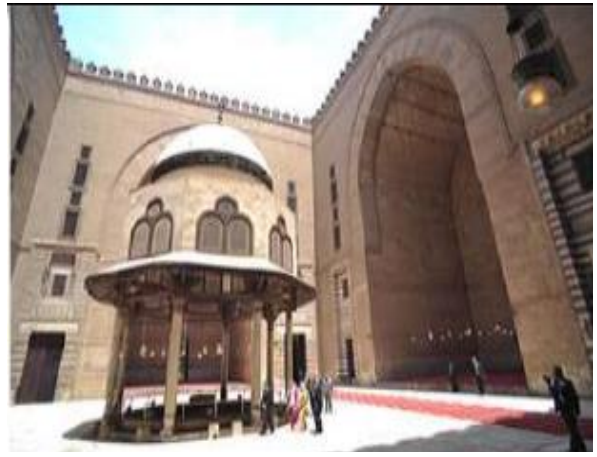

b. School and mosque of Sultan bin Qalawun

Figure 1. Examples of building from limestone in Egypt.

The materials used in this study were natural limestone blocks were cut from a quarry in the road of EL-Sheikh Fadl in Minya, where limestone blocks were impure according to the XRD \& XRF tests. Two types of mortar have been tested in this study.

\section{EXPERIMENTAL PROGRAM AND TEST SET-UP}

The test program aims were studying the behavior of limestone blocks and studying the effect of different parameters on the performance of limestone masonry walls under vertical loads up to failure. So this research studied the mechanical properties of limestone blocks, the properties of limestone masonry prisms and the behavior of limestone masonry walls under vertical load. The parameters effect on the performance of limestone masonry walls are:

1- Type of mortar where two types were

a- Cement mortar (mortar no.(1))

b- Lime mortar (mortar no. (4))

2- Construction system of the walls where three construction system were tested

a- Solid wall

b- Wall with window

c- Wall with door 


\subsection{MECHANICAL PROPERTIES OF NATURAL LIMESTONE}

The mechanical Properties of natural lime stones were determined by carrying out tests such as (absorption test, compressive strength test and splitting tensile strength test). The tests were carried out according to the Egyptian code for the tests as follows:

\subsubsection{THE ABSORPTION TEST}

In this test oven dried limestone units of known weight were placed in an empty tank, and then water was poured on the units at a rate so as to submerge the units in a time period of four hours. Then the units were left submerged for 24 hours. Then specimens were removed from water and weighed and the percentage of the unit absorption was calculated. The average absorption percentage ratio for blocks was $11.708 \%$.

\subsubsection{THE COMPRESSIVE STRENGTH TEST}

The compressive strength must be determined to establish the quality of the masonry units. The blocks were tested under compression loading a $300 \mathrm{KN}$ universal testing machine in the properties and strength of material laboratory, faculty of Engineering at Matarya, Helwan University, Egypt The axial compression strength of the units were calculated from divided the failure load by the area. The average axial compressive strength of the blocks was $14.865 \mathrm{~N} / \mathrm{mm}^{2}$.

\subsubsection{THE SPLITTING TENSILE STRENGTH}

In this research the indirect splitting tensile method was used to determine the tensile strength of limestone units. The compressive loads applied to units were imposed by means of bearing rod giving a lateral tensile stress distributed over almost the height of the units for the split length of the unit. The failure mode of the samples units was splitting of the face shells along the vertical plane between the two line loads. The average splitting tensile strength of the blocks was $0.88 \mathrm{~N} / \mathrm{mm}^{2}$.

\subsection{PROPERTIES OF MORTAR}

The strength of the mortar influences the strength of the masonry in compression, tension and flexure but not to a great degree. According to the Egyptian Code for designing and executing masonry works, two types of mortar were tested; mortar no. 1 contains cement only and mortar no. 4, contains cement and lime. The following Table. 1 shows the mixing ratios of mortars.

\begin{tabular}{|c|c|c|c|}
\hline Mortar Type & Cement Ratio & Lime Ratio & Sand Ratio \\
\hline Mortar no. (1) & 1 & 0 & 2.5 \\
\hline Mortar no. (4) & 1 & 2.5 & 8.75 \\
\hline
\end{tabular}

The compressive strength of the used mortars was estimated by testing mortar cubes of surface area $500 \mathrm{~mm}_{2}$. The average compressive strengths of tested mortars after 28 days for mortar no. 1 and 4 was $(22.95$ and 4.77$) \mathrm{N} / \mathrm{mm}^{2}$ respectively more than the limit of the Egyptian code for designing and executing masonry works. 


\subsection{PROPERTIES OF MASONRY PRISMS}

Masonry is a composite material consists of units and mortar, the interaction of this material was tested as prisms to determine the characteristics of masonry, where these tests was an axial compression test, shear strength test, flexural Tensile strength test and in plane strength test.

\subsubsection{AXIAL COMPRESSION TEST}

The importance of axial compression strength of masonry prisms is that it was the basic of determine the design stress of the load bearing walls and sometimes it used as a quality control measure of the building material. Usually the masonry prism forms from one block with different heights. So, the height of the prism was determined by five blocks as shown in Figure 2. Since the mechanism of this test was to transfer the load from the top to the bottom of the prism so it was necessary to make a capping from the gypsum to provide a flat surface that allows uniform distribution of the load on the loaded area. In this research the masonry prisms have been constructed using two different types of mortar: cement mortar type 1 and lime mortar type 4, and the compression strength.

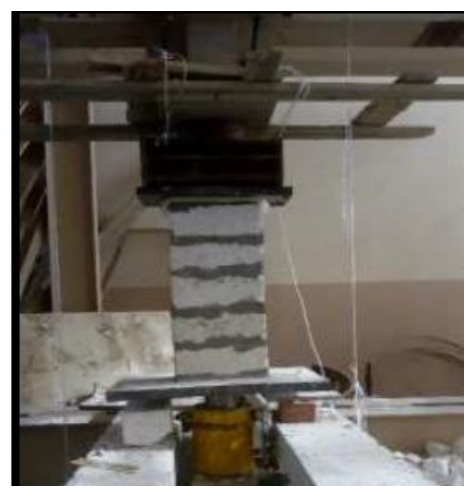

a. Prism constructed using mortar no 1 .

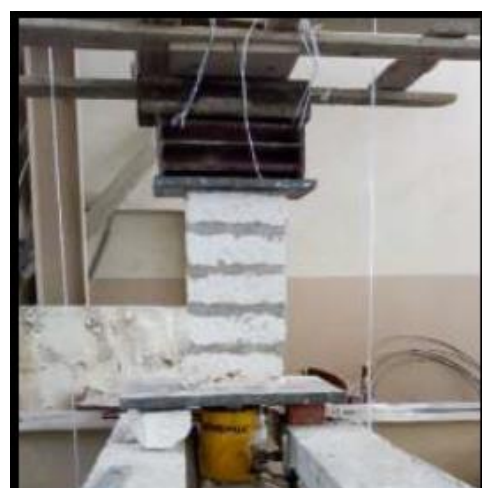

b. Prism constructed using mortar no 4 .

Figure 2. Specimens of prisms under axial compression test before testing

\subsubsection{SHEAR TEST}

Masonry shear walls were intended to resist shear forces due to in-plane lateral loads plus to the effect of axial load and bending. Test to measure the shear strength along mortar bed joints have not been standardized and, as a result, many variations have been developed. Some types of tests that have been used: triplet, modified triplet, couplet and off-axis compression. So, in this research the triplet type has been carried out. The shear stresses at failure were calculated using the following formula $\tau=\frac{P}{2 \mathrm{~A}}$

Where:

$\mathrm{T}=$ shear stresses

$\mathrm{P}=$ failure load

$A=$ net area of contact between the two block 

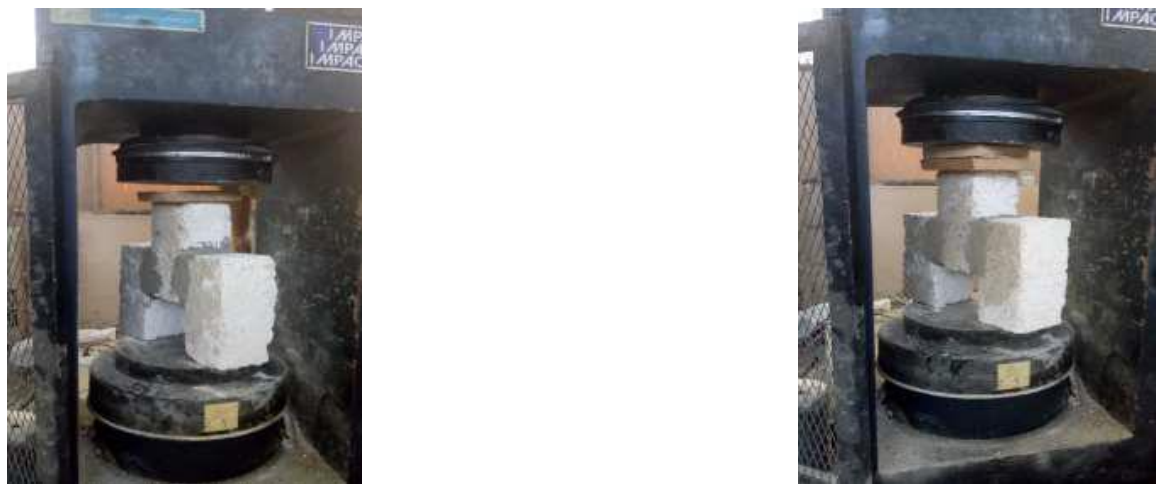

a. Prism constructed using mortar no 1 .

b. Prism constructed using mortar no 4. Figure. 3. Specimens of prisms under shear test before testing

\subsubsection{IN-PLANE TENSILE STRENGTH}

In load bearing masonry buildings, shear walls carry vertical loads and resist the lateral in-plane loads due to wind or earthquakes. This combined loading creates principal tension stresses in the wall leading to tensile cracking when the tensile strength of the masonry was exceeded. The splitting tension test has been very useful for developing an understanding of the factors affecting in-plane tensile strength of masonry. Factors affecting in-plane tensile strength such as:

1- Orientation of the principal tension stress.

2- Mortar type.

3- Strength of masonry unit.

Where the splitting tensile strength determined from the following relations:

$$
\begin{aligned}
& F_{t}=\frac{2 P}{T_{A}} \text { when } \theta=0^{\circ} \\
& F t=\frac{P}{A} \text { when } \theta=90^{\circ} \\
& F t=\frac{0.707 P}{A} \text { when } \theta=45^{\circ}
\end{aligned}
$$

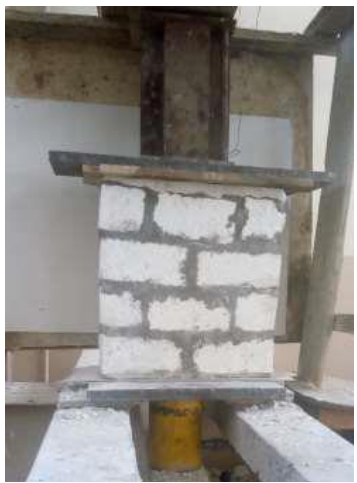

a. Prism constructed using mortar no 1.

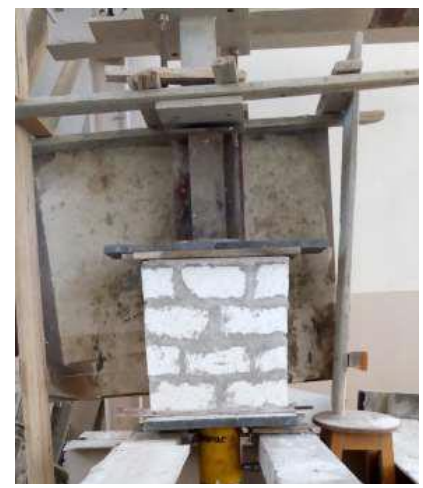

b. Prism constructed using mortar no 4 .

Figure. 4 Specimens of prisms under in-plan splitting tensile test with $\theta=0^{\circ}$ 


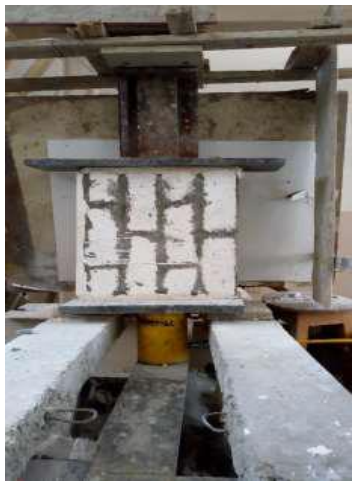

a. Prism constructed using mortar no 1 .

Figure. 5 Specimens of prisms under in-plan splitting tensile test with $\theta=90^{\circ}$

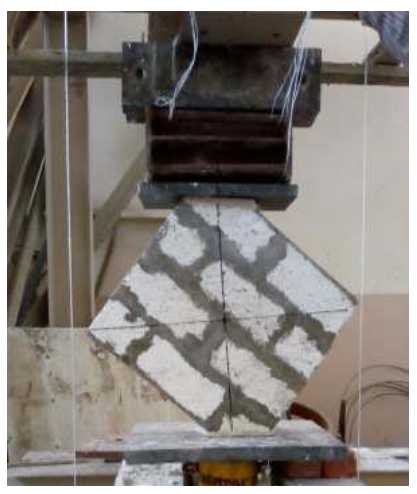

a.Prism constructed using mortar no 1

Figure 6. Specimens of prisms under in-plan splitting tensile test with $\theta=45^{\circ}$

\subsubsection{FLEXURAL TENSILE STRENGTH FOR OUT OF PLANE BENDING}

The flexural tensile strength of masonry for out of plane bending relates to the resistance of walls subject to lateral loads from wind, earthquake, or earth pressure, and to eccentric load or direct bending due to gravity loading. Flexural tensile strength is usually referred to in terms of direction of the tension, that is, either normal to the bed joints, $f^{\prime \prime}{ }_{m}$, or parallel to the bed joints, $f_{t p}^{\prime}$.

\subsubsection{TENSION NORMAL TO BED JOINT}

The method used in this research to determine the flexural tensile strength in this case was ASTM E518., where this method uses beam tests of stack-bonded prisms with prisms heights at least 450mm and either third-point loading, as shown in Figure 6.

\subsubsection{TENSION PARALLEL TO BED JOINTS}

The test methods were developed to determine tensile bend strength normal to the bed joints. However, with some modification, researchers have adopted them to tests for tension parallel to bed joints. For the prism beam tests, the length parallel to the bed joints must usually be at least four units, as shown in Figure 7. 


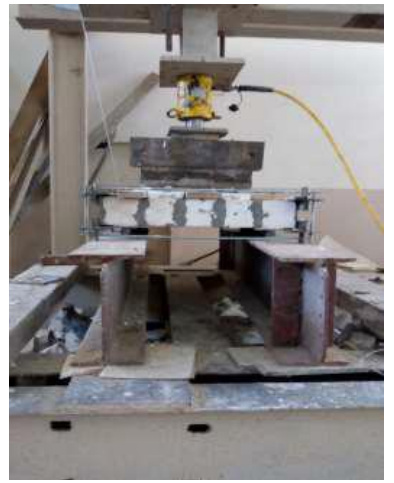

a.Prism constructed using mortar no 1. Figure 7. Prisms under tests for flexural tension normal to bed joints.

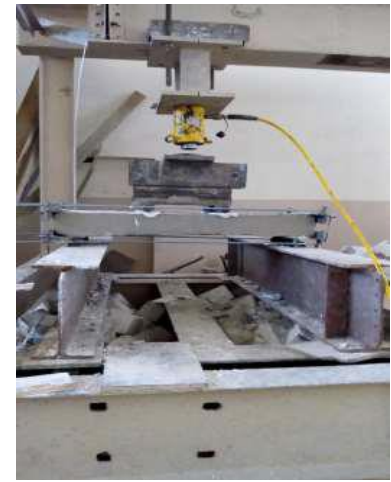

a. Prism constructed using mortar no 1 .

Figure 8. Prisms under tests for flexural tension parallel to bed joints.

Where the flexural tensile strength determined from the following relation: $f_{t}=\frac{M Y}{I}$

$f_{t}^{\prime} \rightarrow$ Flexural tensile strength

$M \rightarrow$ Bending moment

$I \rightarrow$ Moment of Inertia

\subsection{WALL CONSTRUCTION}

In this research studied the effect of different parameters was studied on the performance of limestone masonry wall, so the tested parameters are:

1- Wall system was used as shown in Figure 8.

a- Solid wall (W1 and W2)

b- Wall with window (W3 and W4)

c- Wall with door (W5 and W6)

2- Mortar used was different where two type of mortar

a- Cement mortar no 1- (W1, W3, W5)

b- Lime motor mortar no 2 - (W2, W4, W6)

All walls were constructed on reinforced concrete base beam to facilitate movement and placement of the specimens on the test frame. The dimension of this base was (250x250x2500) $\mathrm{mm}$ and it was reinforced with $2 \varphi 12$ bottom and $2 \varphi 10$ top. The walls 
were constructed in the concrete testing laboratory in faculty of engineering at matarya, Helwan University by a qualified mason using two type of mortar as shown in figure10, after a week the walls were tested under a vertical load. A concrete beam was cast at the top of every wall to act as a distribution beam for application of vertical load. The dimension of this beam was $(25 \times 25 \times 250) \mathrm{mm}$. The walls tests were performed using two points loading because this method of loading makes the wall exposed to pure bending without shear force. The walls were tested after one week of construction, digital load cell of capacity $1500 \mathrm{KN}$ with accuracy of $0.1 \mathrm{KN}$ was adopted to measure the applied load as shown in figure 9. The value of loads was recorded from the monitor connected to the load cell.

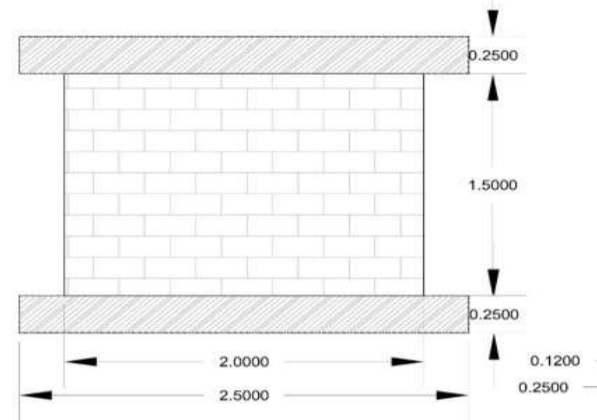

a.Solid wall

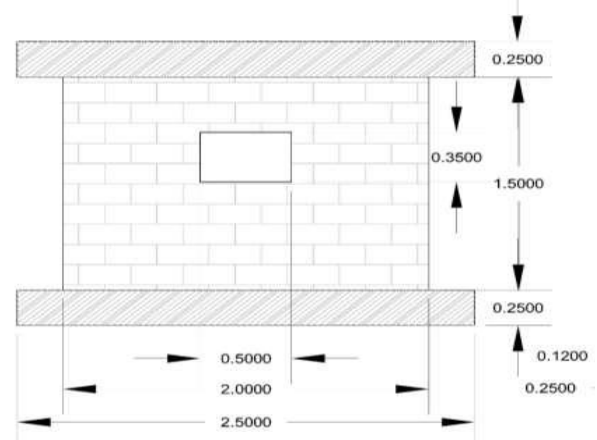

b. Wall with window

Figure 9. Tested wall specimens

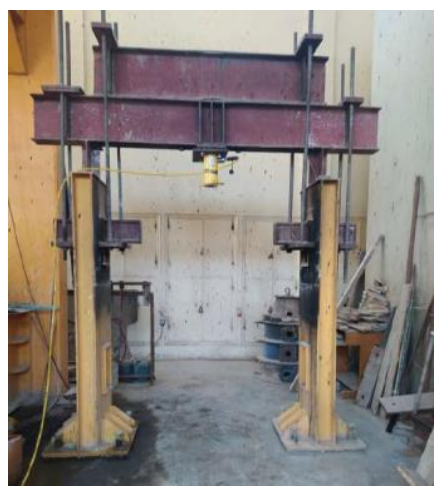

Figure 10. Test Setup.

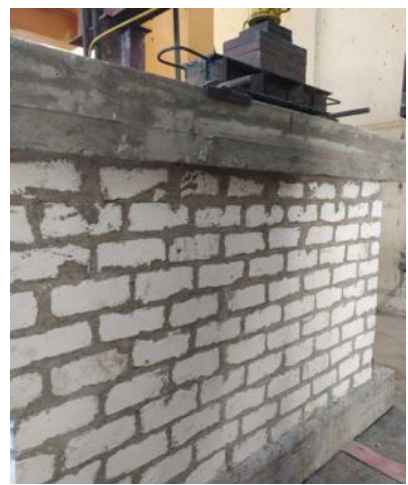

Figure 11. Wall under testing.

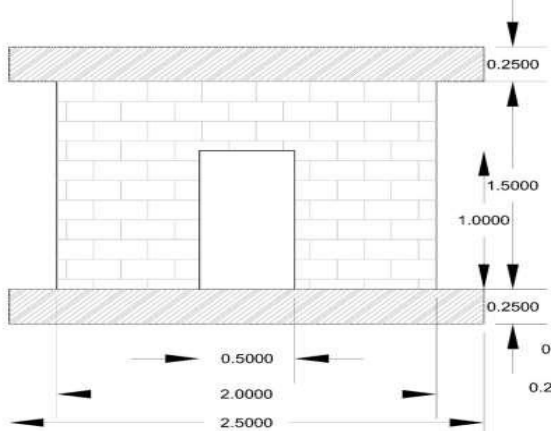

c. Wall with door

\section{CV8}




\section{EXPERIMENTAL RESULTS}

The wall specimens were continuously loaded up to failure, the data was recorded using monitor connected to the load cell.

\subsection{MASONRY PRISMS}

The results of prisms' test, these tests were: axial compression test, shear strength test, in-plane tensile strength and out of plane tensile strength as mentioned following.

\subsubsection{AXIAL COMPRESSIVE TEST}

The failure mode of the specimens was the shear compression failure as shown in Figure. 12. Vertical splitting cracks was formed along the height of the assemblages, these cracks were vertically in blocks because of the lateral tensile stresses in the blocks and then followed by cracks in the bed joints of mortar by increasing the vertical load. Where the first crack occurred in the assemblages were constructed using mortar 1 at the loads (85,87and 90) $\mathrm{KN}$ respectively, while the first crack occurred in the assemblages were constructed using mortar 4 at loads (65, 74 and 65) $\mathrm{KN}$ respectively. The average compressive strength of prisms was constructed using mortar 1 and mortar 4 was $(8.8$ and 6.3$) \mathrm{N} / \mathrm{mm}^{2}$ respectively, the results show, the specimens were constructed by using mortar type no1 have greater resistance to axial compression than the specimens were constructed using mortar type no 4 because the strength of mortar had effected on the compressive strength of assemblages. And the stress strain curves for all specimens as shown in Figure12.

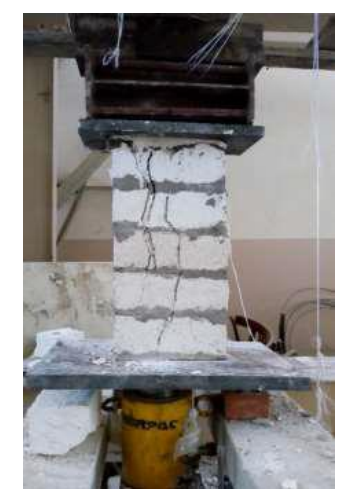

a. Prism constructed using mortar no1.

Figure 12. Failure mode of masonry pri

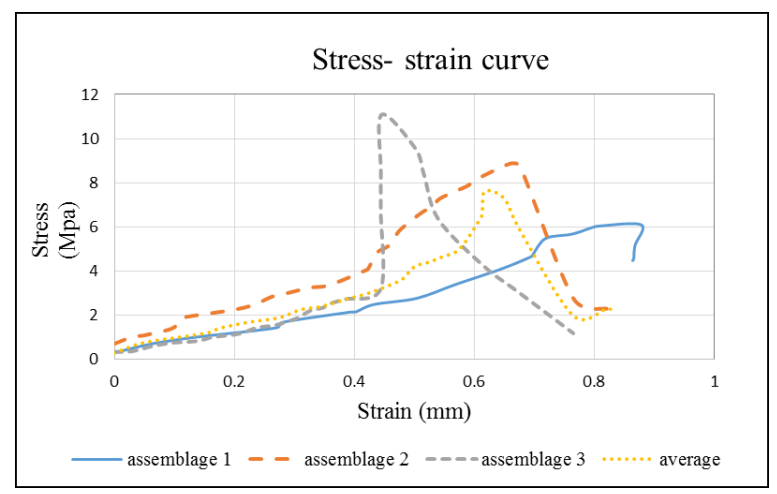

a. Prisms constructed using mortar no

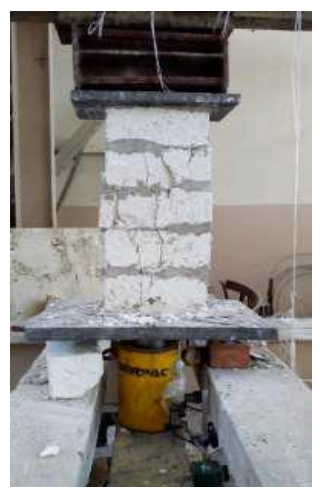

b. Prism constructed using mortar no 4 . prisms under axial compression test

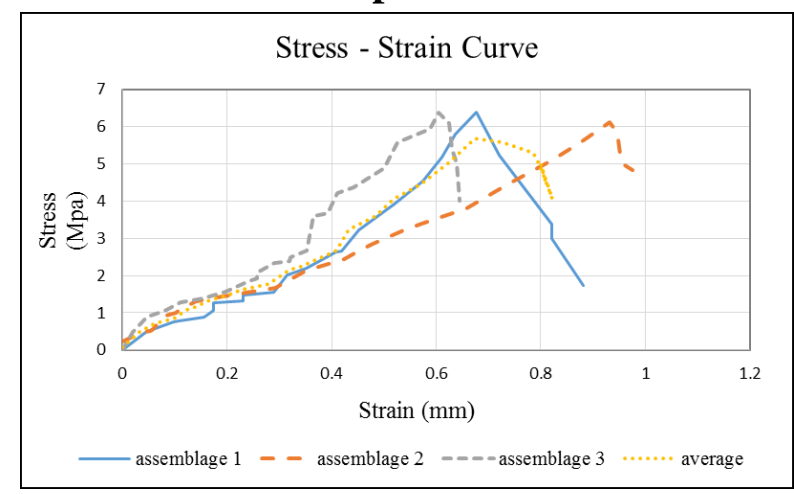

b. Prisms constructed using mortar no 4.

Figure 12. The stress - strain curve of prisms under axial compression test 


\subsubsection{MODULUS OF ELASTICITY}

The modulus of Elasticity of masonry was determined as the relationship between stress - strain diagram from the compressive strength of masonry [3]. So from previous stress - strain curves $E_{m}$ of limestone blocks were constructed from mortar no 1 and mortar no 4 is (6487 and 5719) N/mm respectively. The modulus of elasticity $E_{m}$ is traditionally calculated by equation $E_{m}=K f^{\prime}{ }_{m}$, where $K$ is the coefficient depends on the type of used material. Base on the previous results of the compressive strength of the prisms, a vale of $K$ in order to 900 was found to be satisfactory for determination of the modulus of elasticity $E_{m}$ of the limestone.

\subsubsection{SHEAR STRENGTH TEST}

The failure initiated by a boding at the block and the mortar interface and a sudden failure occurred after the formation of a visible crack at the mortar block interface as shown in figure 13. The average shear strength of the prisms were constructed by using mortar no1 and mortar no 4 was $(1.8$ and 2.1$) \mathrm{N} / \mathrm{mm}^{2}$ respectively.
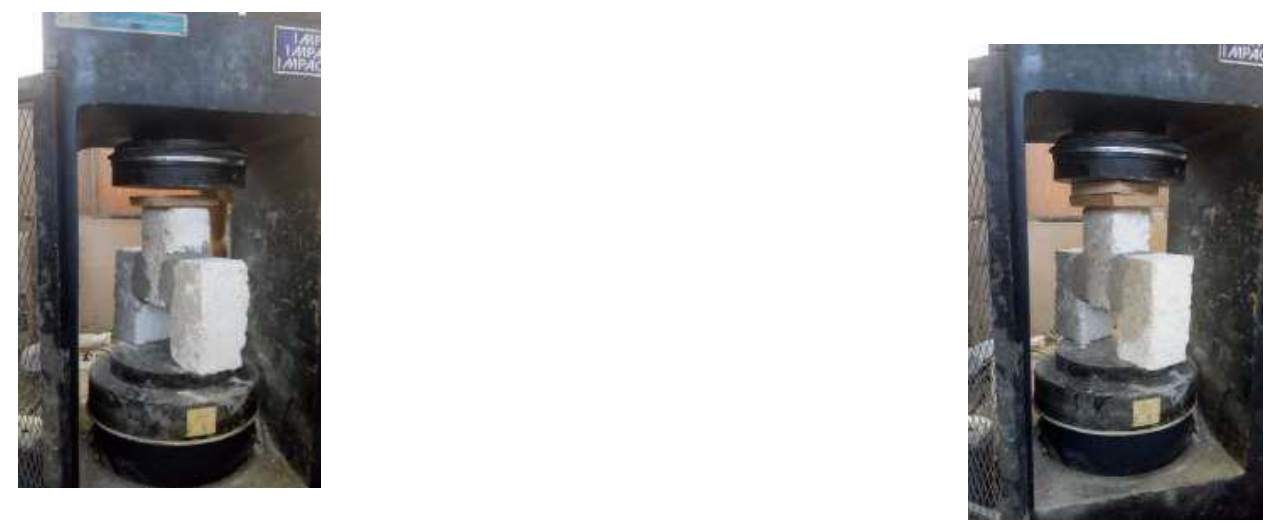

a. Prism constructed using mortar no. (1) b. Prism constructed using mortar no. (4) Figure 13. The failure mode of masonry prisms under shear test

\subsubsection{IN-PLANE TENSILE STRENGTH}

To carry out this test three specimens were constructed by using mortar type 1 and another three specimens were constructed using mortar type 4 have been constructed in each case of load.

\subsubsection{IN CASE OF LINE LOADS NORMAL TO THE BED JOINTS}

For line loads normal to the bed joints, the cracks initiated along the block then it passed along the block and the mortar interface at the head joint in case of assemblages were constructed by using mortar no 1 , and the first cracks in the assemblages occurred at loads (134, 163 and 90) $\mathrm{KN}$ respectively. While in case of assemblages was constructed using mortar no 4 the cracks initiated along the block then it passed along the block and the mortar interface at the bed joint and then passed along the block and the mortar interface at the head joint, and the first cracks occurred in the assemblages at loads (80, 38 and 60) $\mathrm{KN}$ respectively as shown in figure 14. And the average in plane tensile strength in this case of loading for prisms were constructing using mortar no 1 and mortar no 4 was (4.0 and 3.9) N/mm ${ }^{2}$ respectively. 
So, the specimens were constructed using mortar type no 1 have greater resistance to splitting tensile than the specimens constructed using mortar type no 4 in case of splitting tension parallel to bed joints. And the stress - strain curves of all specimens as shown in figure 15 .

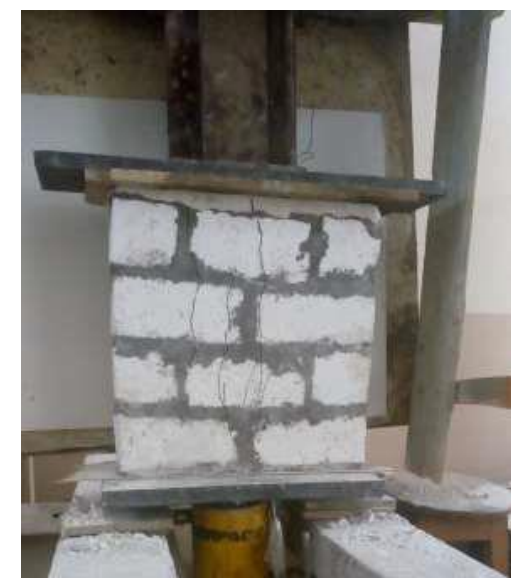

a. Prism constructed using mortar no1. Figure 14. Failure mode of prisms under in-plan splitting tensile test with $\theta=0^{\circ}$

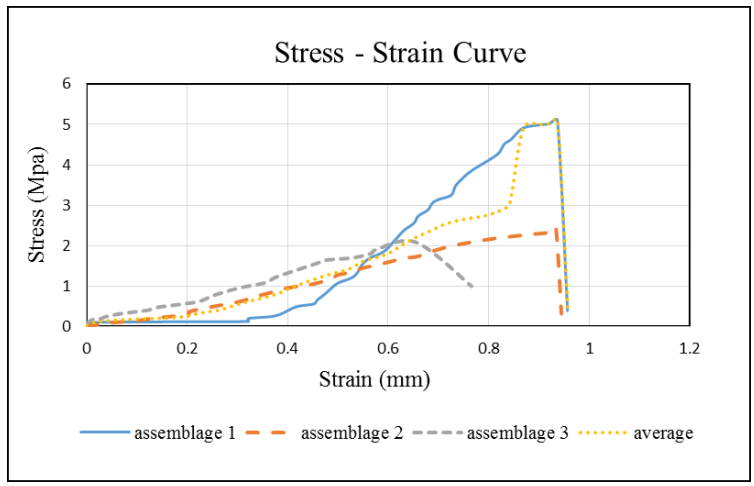

a. Prisms constructed using mortar no 1.

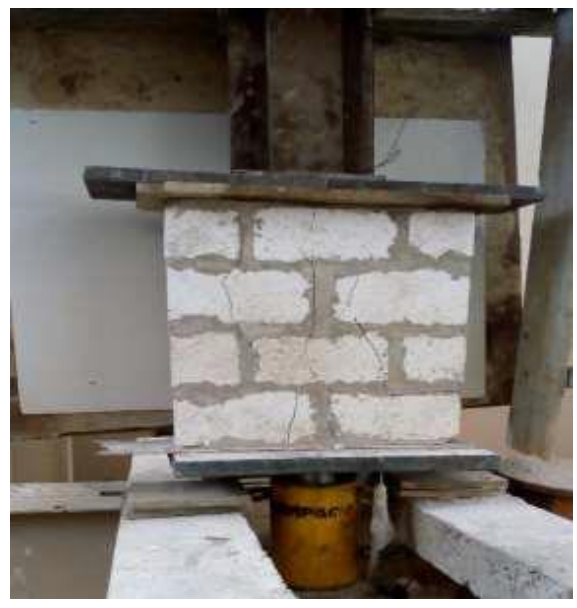

b. Prism constructed using mortar no 4.

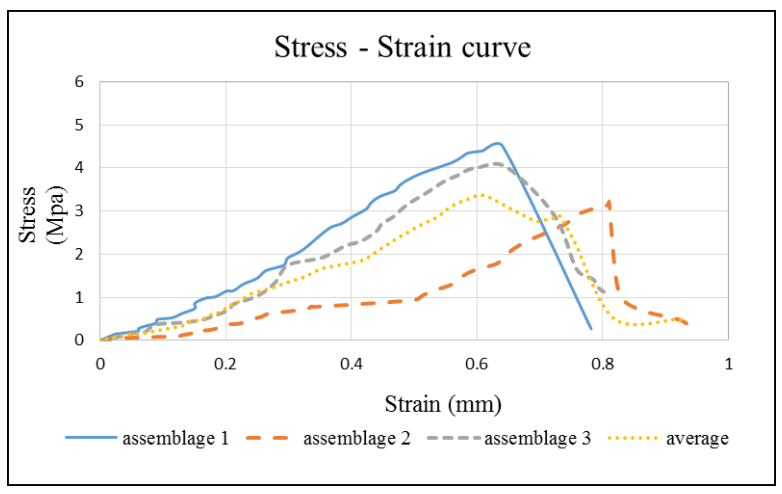

b. Prisms constructed using mortar no 4.

Figure 15. The stress - strain curves of prisms under in-plan splitting tensile test with $\theta=$ $\mathbf{0}^{\circ}$

\subsubsection{IN CASE OF LINE LOADS PARALLEL TO THE BED JOINTS}

For line loads parallel to the bed joints, the cracks initiated along the block and the mortar interface at the bed joints and passing through it only in both cases of assemblages were constructed using mortar no1 and assemblages were constructed using mortar no 4 . The first cracks in the assemblages were constructed by using mortar no 1 occurred at loads $(41,56$ and 61) $\mathrm{KN}$ respectively, while the first cracks occurred in the assemblages was constructed by using mortar no 4 at loads $(33,41$ and 57) $\mathrm{KN}$ respectively as shown in Figure 16, and the average in- plan tensile strength in this case of loading of prisms were constructed by using mortar no 1 and mortar no 2 was (4.8 and 3.0) N/mm ${ }^{2}$ respectively. As shown in Figure 17, can conclude that the specimens were constructed using mortar type no 1 have greater resistance to splitting tensile than the specimens constructed using mortar type no 4 in case of splitting tension normal to bed joints. 


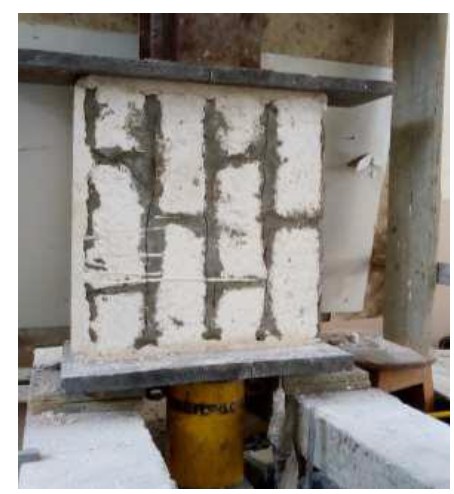

a. Prism constructed using mortar no1.

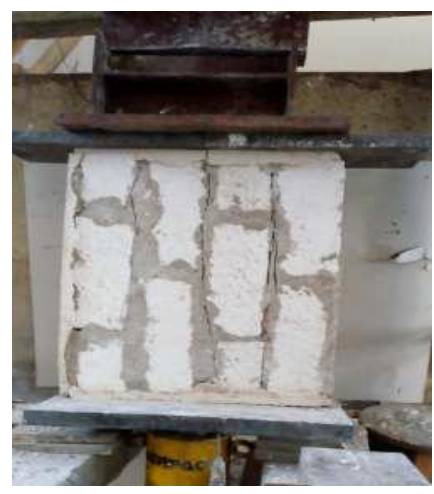

b. Prism constructed using mortar no 4.

Figure 16. The failure mode of prisms under in-plan splitting tensile test with $\theta=90^{\circ}$

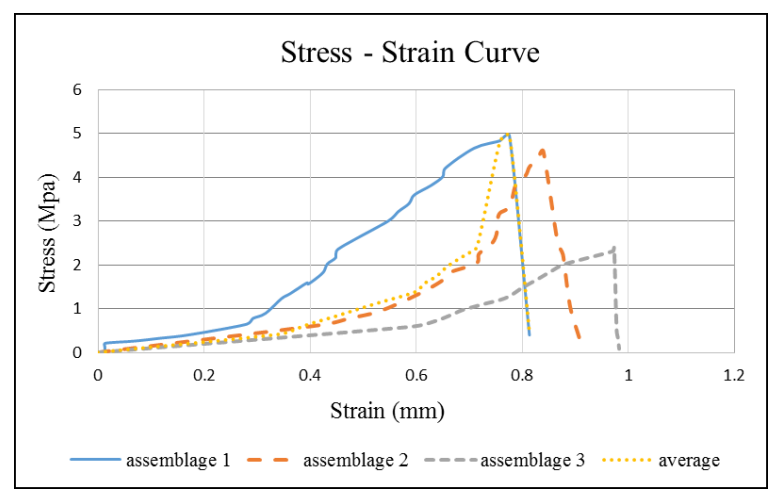

a.Prisms constructed using mortar no1.

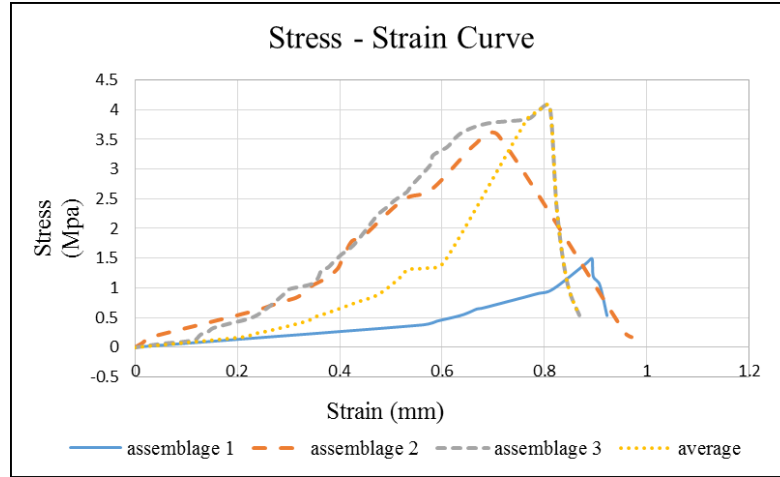

b. Prisms constructed using mortar no 4.

Figure17. Stress - strain curves of prisms under in-plan splitting tensile test with $\theta=90^{\circ}$

\subsubsection{IN CASE OF LINE LOADS ORIENTED AT $45^{\circ}$ FROM THE BED JOINTS}

For line loads oriented at $45^{\circ}$ from the bed joints the cracks initiated along the block and the mortar interface at the head joints and passing through the block and the mortar interface at the bed joints in both cases of assemblages were constructed using mortar no1 and assemblages were constructed using mortar no 4 . The first cracks in the assemblages were constructed using mortar no 1 occurred at loads $(8.8,10.7$ and 13.8) $\mathrm{KN}$ respectively, while the first cracks occurred in the assemblages were constructed using mortar no 4 at loads (14, 16 and 15) $\mathrm{KN}$ respectively as shown in Figure 18. The average in plane tensile strength in this case of loading of prisms were constructed using mortar no 1 and mortar no 4 was (1.6 and 1.6) N/mm respectively. So, the specimens were constructed using mortar type no 1 have almost equal resistance to splitting tensile to the specimens constructed using mortar type no 4 in case of line load orientated at $45^{\circ}$ from the bed joints. And the stress - strain curves for all specimens as shown in Figure 19. 


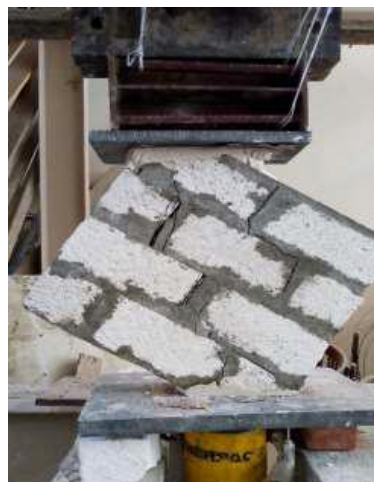

a. Prism constructed using mortar no 1

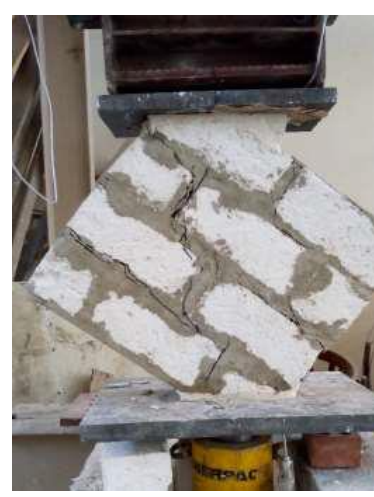
b. Prism constructed using mortar no 4
plan splitting tensile test with $\theta=45^{\circ}$

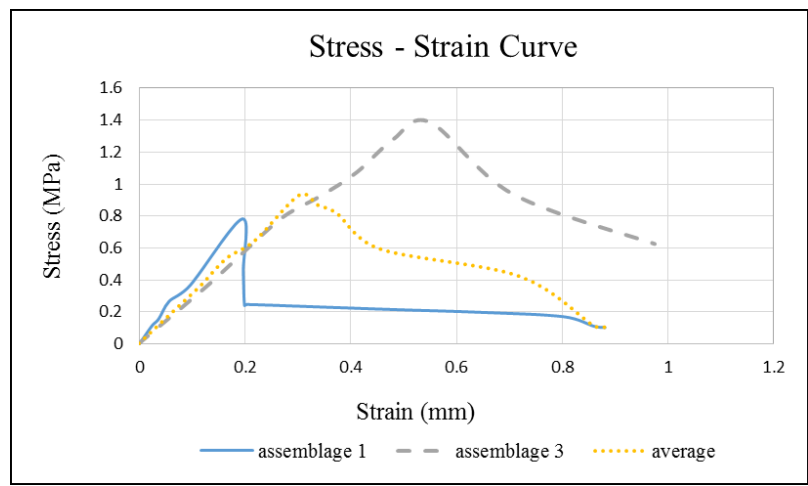

a. Prisms constructed using mortar no. 1

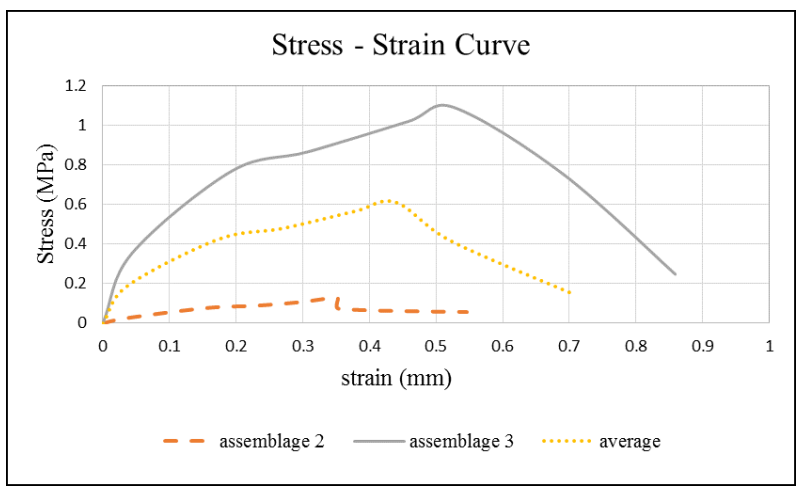

b. Prisms constructed using mortar no. 4 Figure 19. Stress - strain curves of prisms under in-plan splitting tensile test with $\theta=$

$45^{\circ}$

\subsubsection{FLEXURAL TENSILE STRENGTH FOR OUT OF PLANE BENDING}

To carry out this test three specimens were constructed using mortar type 1 and another three specimens were constructed using mortar type 4 have been constructed in each case of load.

\subsubsection{Flexural tension normal to bed joints}

For flexural tension normal to the bed joints, failure consists of connecting of the mortar from the unit along the bed joint. The first cracks in the assemblages were constructed using mortar no 1 occurred at loads (18.5, 20.5 and 10.1) KN respectively, while the first cracks occurred in the assemblages were constructed using mortar no 4 at loads (13.5, 7.3 and 6.1) KN respectively as shown in Figure 20, and the average flexural tensile strength in this case of loading of the prisms were constructed using mortar no 1 and mortar no 4 was $(4.4$ and 1.8$) \mathrm{N} / \mathrm{mm}^{2}$ respectively. 

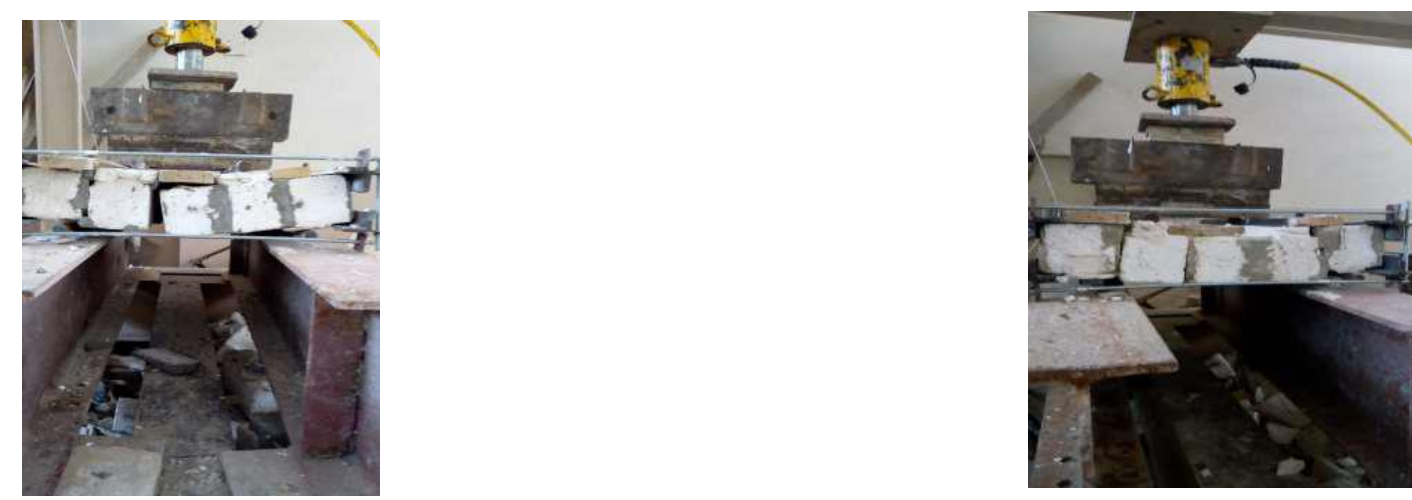

\section{a. Prism constructed using mortar no 1 b. Prism constructed using mortar no 4 Figure 20. Failure mode of prisms - out of plane bending.}

\subsubsection{Flexural tension parallel to bed joints}

For masonry with relatively strong units and weak mortar joints, flexural failure for tension parallel to the bed joints can occur through a combination of tensile and shear connecting in the head and bed joints. The first cracks in the assemblages were constructed using mortar no 1 occurred at loads (5.5, 5.7 and 5.9) $\mathrm{KN}$ respectively, while the first cracks occurred in the assemblages were constructed using mortar no 4 at loads (3.5, 3.6 and 4.5) $\mathrm{KN}$ respectively as shown in Figure 21, and the average flexural tensile strength in this case of load of prism were constructed using mortar no 1 and mortar no 4 was $(0.82$ and 0.61$) \mathrm{N} / \mathrm{mm}^{2}$ respectively.

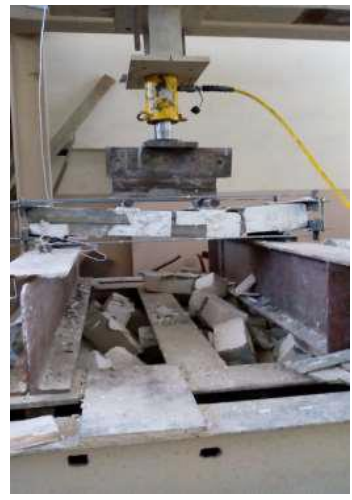

a. Prism constructed using mortar no 1

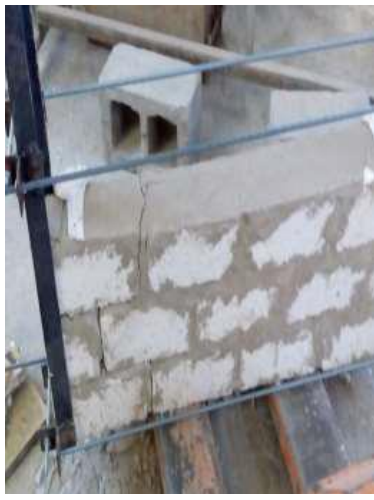

b. Prism constructed using mortar no 4 Figure 21. Failure mode of out of plane bending-tension parallel to bed joints.

\subsection{MASONRY WALLS}

The scope of these tests is evaluated the effect of the different parameters on the behavior of walls. These parameters was divided into two parameters, the first one was the mortar type by using in the construction of walls and another one was the existing of opening in the walls. So six walls with dimensions (2000x120x1500) mm are tested under axial load to examine the behavior and mode of failure, where W1 was a solid wall and constructed using mortar no1, W2 was another solid wall but constructed using mortar no 4 , W3 was a wall with window and constructed using 
mortar no 1, W4 was another wall with window but constructed using mortar no 4, W5 was a wall with door and constructed using mortar no 1 and W6 was another wall with door but constructed using mortar no 4 , the average stress on the wall section was calculated by dividing the applied load by the gross cross sectional area of the wall.

For W1 and W2, cracks were initiated along the upper head joints and then passing through the bed joints and then the blocks. And by increasing the loads the more cracks had appeared in the each walls W1 and W2 until failure load (607 and 462) KN respectively as shown in Figure 22.

For W3 and W4, cracks were initiated along the upper head joints and then passing through the bed joints and the blocks. The blocks around the window have been cracked before the other blocks because the opening was weaken the blocks, and by increasing the loads the more cracks had appeared in the each walls W3 and W4 until failure load (350 and 252) KN respectively as shown in Figure 23. For W5 and W6 Cracks initiated along the upper head joints and then passing through the bed joints and the blocks. The blocks above the door have been cracked before the other blocks because the opening was weaken the blocks. And by increasing the loads the more cracks had appeared in the each walls W5 and W6 until failure load (330 and 233) KN respectively as shown in Figure 24. The results of compressive strength of wall as shown in Table (2). Also, Figure 25 shows the variation of the failure stress for all the walls.

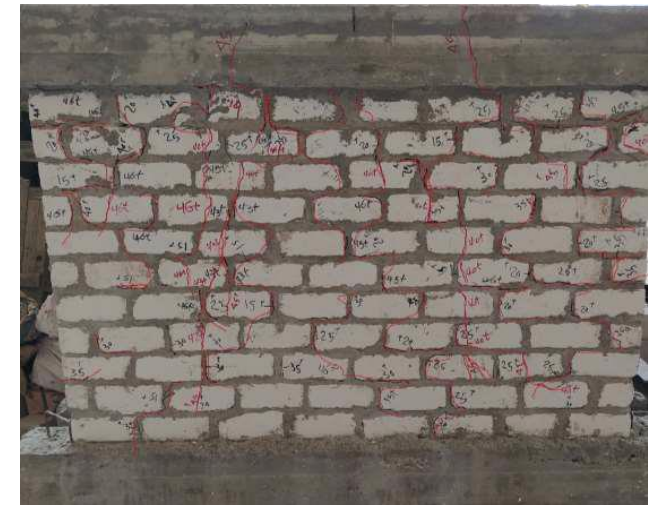

a. Solid wall (W1)

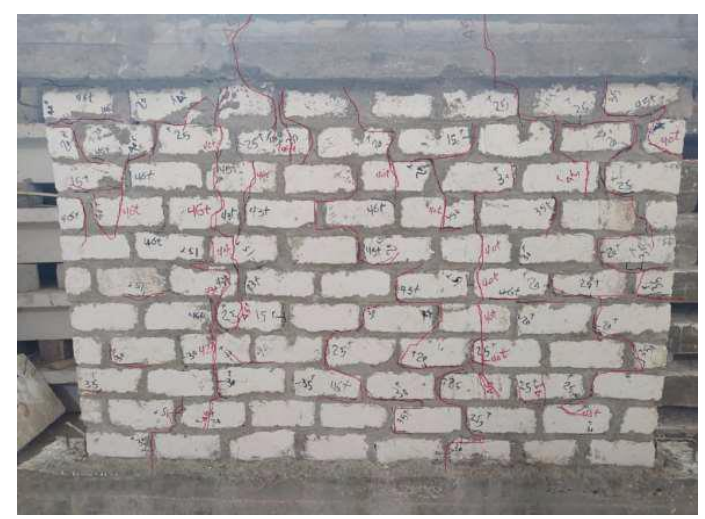

b. Solid wall (W2)

Figure 22. Crack pattern 


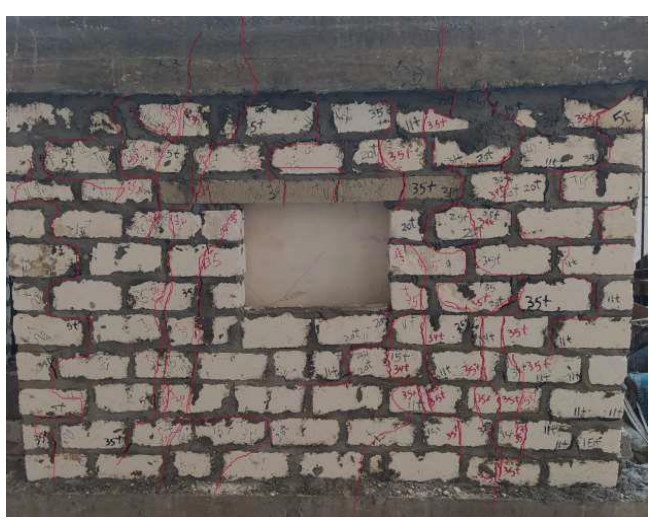

a. Wall ( W3)

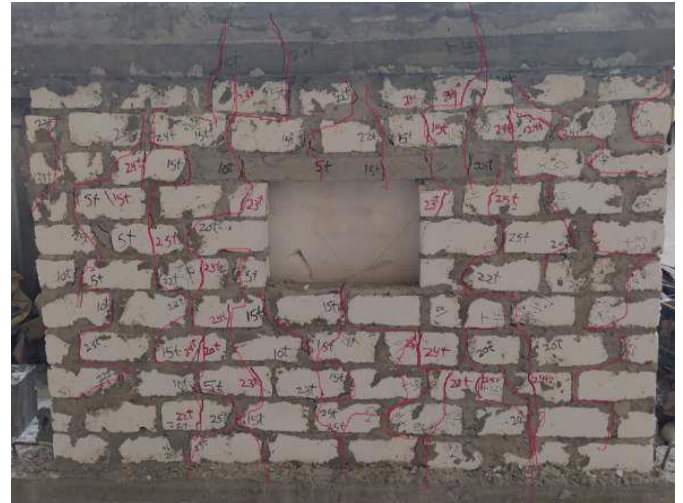

b. Wall (W4)

\section{Figure 23. Crack pattern}

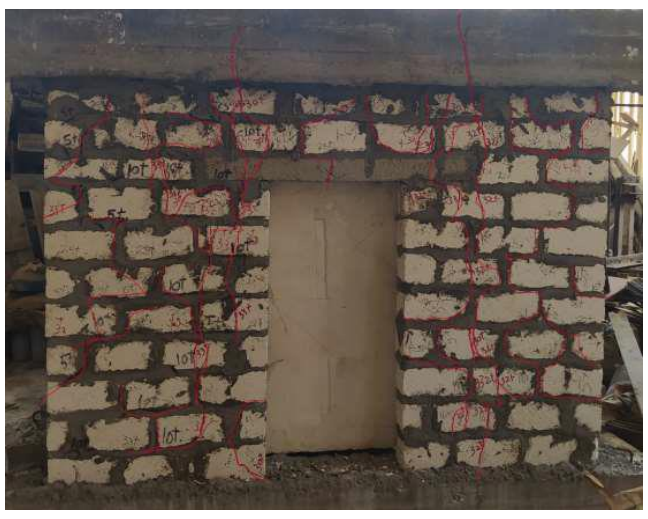

a. Wall ( W5)

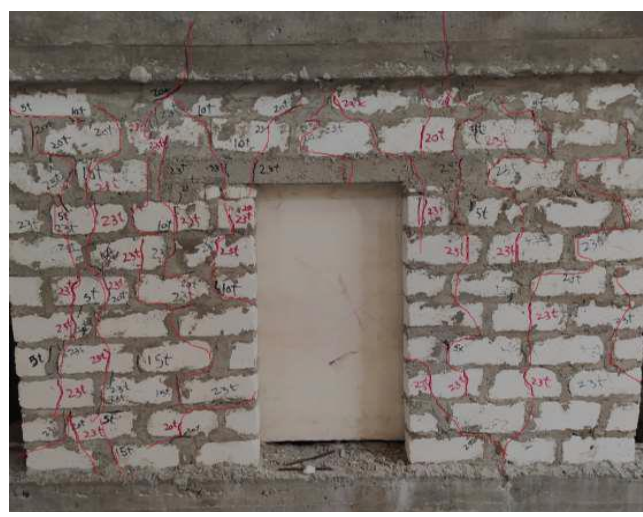

b. Wall ( W6)

Figure 24. Crack pattern

Table (2) Failure load of masonry walls

\begin{tabular}{|c|c|c|c|c|}
\hline $\begin{array}{c}\text { Wall } \\
\text { no. }\end{array}$ & $\begin{array}{c}\text { Wall dimensions } \\
(\mathrm{mm})\end{array}$ & Mortar no. & $\begin{array}{c}\text { Failure load } \\
(\mathrm{KN})\end{array}$ & $\begin{array}{c}\text { Stress at failure } \\
\left(\mathrm{N} / \mathrm{mm}^{2}\right)\end{array}$ \\
\hline W1 & $2000 \times 120 \times 1500$ & 1 & 607 & 2.5 \\
\hline W2 & $2000 \times 120 \times 1500$ & 4 & 462 & 1.9 \\
\hline W3 & $2000 \times 120 \times 1500$ & 1 & 350 & 1.5 \\
\hline W4 & $2000 \times 120 \times 1500$ & 4 & 252 & 1.1 \\
\hline W5 & $2000 \times 120 \times 1500$ & 1 & 330 & 1.4 \\
\hline W6 & $2000 \times 120 \times 1500$ & 4 & 233 & 1.0 \\
\hline
\end{tabular}

From these results, it can notice that the two parameter had effected on the walls strength as it is presented in fig. 25 . 


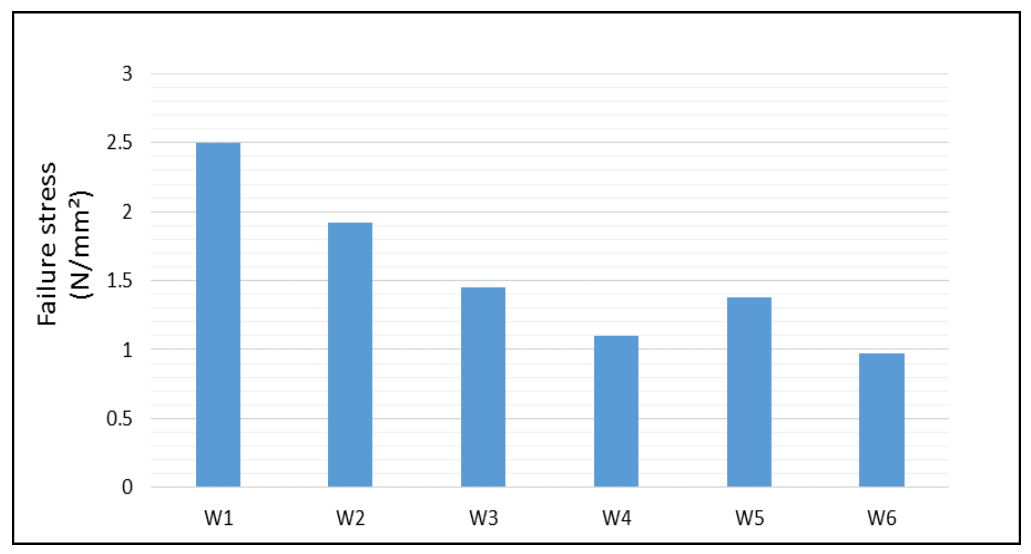

Figure 25. Wall failure stress

\section{ANALYSIS OF EXPERIMENTAL RESULTS}

The effect of the different parameters on the wall performance is presented in this section. Those parameters include the mortar strength and the wall system construction. The cement mortar type effect the overall strength of the walls as shown in Figure 26, Where, the existing of opening in the wall decreasing the overall strength of the walls.

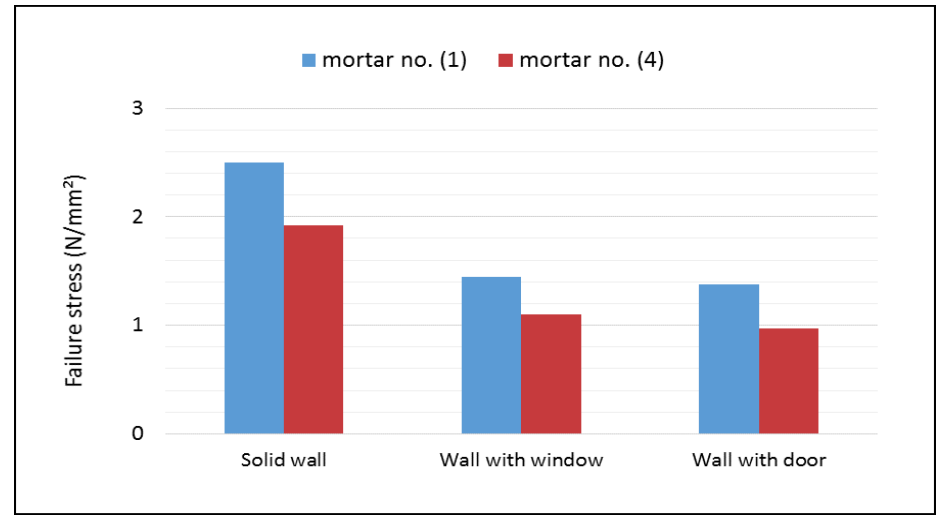

Figure 26. Effect of mortar type on strength of wall

For walls were constructed using mortar no 1 (W1,W3 and W5) the ultimate failure load of W3 was less than the ultimate failure load of W1 by $42 \%$, and the ultimate failure load of W5 was less than the ultimate failure load of W1 by $46 \%$ and For walls were constructed using mortar no 4 (W2,W4 and W6) the ultimate failure load of W4 was less than the ultimate failure load of W2 by $45 \%$, and the ultimate failure load of W6 was less than the ultimate failure load of W2 by 49\% as shown in Figure 27. 


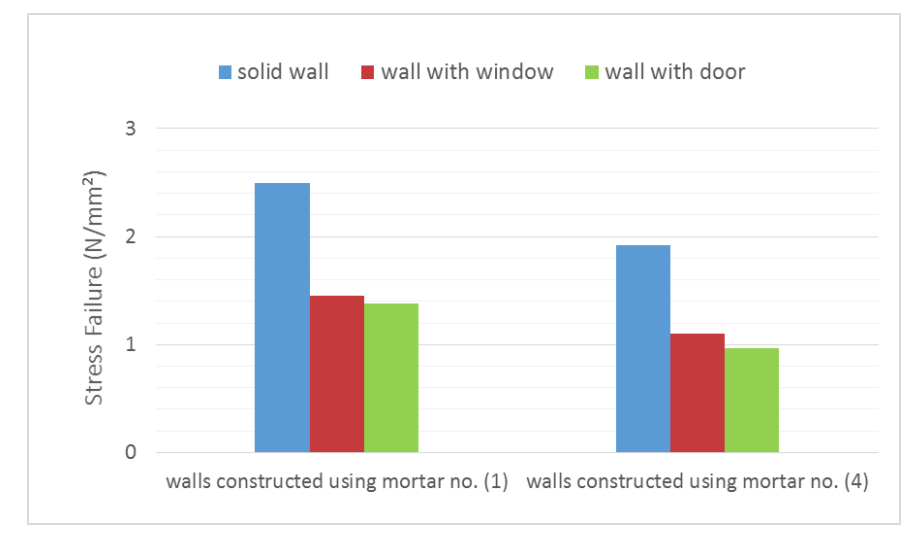

\section{Figure 27. Effect of existing opening on the strength of walls}

\section{Conclusions}

1- The type of mortar influence on the strength of wall, where the walls constructed using mortar no 1 (cement mortar) was stronger than the walls constructed using mortar no 4 (lime mortar) by $30 \%$.

2- The existing opening in the wall decreasing the overall strength of the walls by $44 \%$ in case of existing window and by $47 \%$ in case of existing door.

3- The cracks in all the walls started from the head joints then passing through the bed joints and the blocks.

4- The prisms were constructed using mortar no1 have almost equal resistance to splitting tensile to the prisms were constructed using mortar no 4 in case of line load oriented at $45^{\circ}$ from the bed joint.

5- The prisms constructed using mortar no 4 have greater resistance to shear than the prisms constructed using mortar no 1 by $18 \%$.

6- Overall the prisms and walls which have been constructed using mortar no1 are stronger than the prisms and walls have been constructed using mortar no 4.

\section{References}

1- Fouda, A. A.,(2001), "Construction and behavior of masonry in wall bearing structure", Faculty of Engineering, Shoubra, Banha University.

2- Wijanto, L. S., (2007), "Seismic assessment of unreinforced masonry walls", Faculty of Engineering, University of Canterbury, Christchurch, Newzeland.

3- Tahawy, M. Y., (2009), "Behavior of stone masonry walls under vertical loads", Faculty of Engineering, Cairo University.

4- El sayed, T. A., (2010), "Axial compression of lime stone masonry walls in Egypt", Faculty of Engineering Matteria, Helwan University, Engineering research journal 126, June 2010.

5- The Egyptian Code for Designing and Executing Masonry Works. 